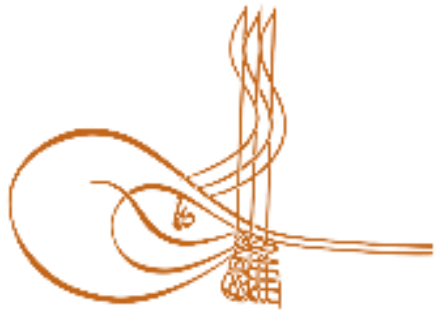

www.turkishstudies.net/social
Turkish Studies - Social Sciences

eISSN: $2667-5617$

Research Article / Araşttrma Makalesi

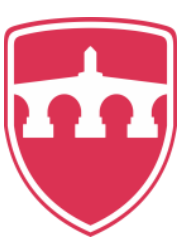

INTERNATIONAL

BALKAN

UNIVERSITY

Sponsored by IBU

\title{
Yabancı Uyruklu Öğrencilerin Kültürlerarası İletişim Kaygısı ile Yalnızlık Düzeyleri Arasında Bir Bağlantı Var mı?
}

\author{
Is There a Connection Between Intercultural Communication Apprehension and Loneliness Levels \\ of Foreign Students?
}

\author{
Şükrü Balcı ${ }^{*}$ - Nesrin Öğüt** ${ }^{* *}$ Nidal Barbakh***
}

\begin{abstract}
Intercultural communication apprehension is a concept that expresses the fears experienced in interaction with different cultures or groups. During the first interactions of people with different cultures and habits, the lack of information about each other increases the uncertainty; this triggers the anxiety or anxiety of the interacting people. When they have a high level of concern about communication, they may tend to avoid or withdraw from communication with others. These uncertainties and anxiety in human relations; it jeopardizes effective communication in an intercultural context. This indicates that there may be a connection between loneliness and intercultural communication apprehension, especially among foreign nationals. This research aims to investigate the relationship between loneliness and intercultural communication apprehension. Data were collected by face to face questionnaire technique from 200 foreign students. Research findings indicate that more than half of the participants have intercultural communication apprehension. Intercultural communication apprehension levels of both male and female have similar values. Intercultural communication apprehension level of those who live in a different country outside the hot topic in Turkey; it is higher than those who have negative attitudes in this regard. The level of intercultural communication apprehension was a significant positive predictor of loneliness score. As the intercultural communication apprehension level of foreign students increased; there is also an increase in the level of loneliness.
\end{abstract}

Structured Abstract: Today, when intercultural contacts have intensified at the individual and social level, it has become inevitable for people to meet and communicate with individuals from different cultures for various reasons. In particular, the developments occurring in many factors such as information, transportation

\footnotetext{
${ }^{*}$ Prof. Dr., Selçuk Üniversitesi, İletişim Fakültesi, Gazetecilik Bölümü

Prof. Dr., Selcuk University, Faculty of Communication, Journalism Department

ORCID 0000- 0002-0477-0622

sukrubalci@selcuk.edu.tr

** Dr., Konya İl Sağlık Müdürlüğü

Ph.D., Konya Provincial Health Directorate

ORCID 0000- 0002-9026-0839

nogut42@hotmail.com

**** Selçuk Üniversitesi Sosyal Bilimler Enstitüsü Gazetecilik Anabilim Dalı Doktora Öğrencisi

Selcuk University Institute of Social Sciences, Ph.D. in Journalism

ORCID 0000-0003-2970-3327
}

Cite as/ Atıf: Balcı Ş., Öğüt, N., Barbakh, N. (2020). Yabancı uyruklu öğrencilerin kültürlerarası iletişim kaygısı ile yalnızlık düzeyleri arasında bir bağlantı var mı?, Turkish Studies - Social, 15(3), 965-982. https://dx.doi.org/10.29228/TurkishStudies.39411

Received/Geliş: 21 October/Ekim 2019

Accepted/Kabul: 25 April/Nisan 2020

Copyright $(C)$ INTAC LTD, Turkey

Checked by plagiarism software

Published/Yayın: 30 April/Nisan 2020

CC BY-NC 4.0 
and communication technologies along with globalization; Increasing population mobility between countries has accelerated the encounters of different cultures in various fields such as economy, politics, tourism and education and intercultural interactions have increased. In parallel with the intensification of intercultural contact, there has been an increase in international mobility. As a result of all these developments, the concept of intercultural communication has become an important issue to be emphasized. In general, intercultural communication is a symbolic and interactive shopping process between people with different cultural groups, sub-cultural backgrounds, knowledge and experience. In other words, it is the interactions of people living in the same region, country, city or street in their relations with each other (Öğ̈̈t, 2018; Yağbasan, 2016).

With globalization, developments in information technologies have increased opportunities for intercultural people and interactions. When individuals with different cultures do not have enough information about each other in their first encounter, it will cause uncertainty to increase. This, in turn, will increase the anxiety and anxiety of the individuals in communication. When interacting individuals have a high anxiety about communicating, they may avoid communicating with others or tend to withdraw. These uncertainties and anxiety in interpersonal relationships; endangers effective communication in an intercultural context. As a result of all these developments, it is important to know the level of intercultural communication anxiety of the individuals so that people can communicate effectively with a different culture, individuals do not feel foreign in intercultural situations and prevent possible communication conflicts. In addition, if individuals' intercultural communication anxiety levels can be reduced, their willingness to communicate with a different culture will be prevented as well as their loneliness. In this study, which was carried out to determine whether there is a connection between the intercultural communication anxiety and loneliness levels of foreign students, the foreign students studying at Selçuk University were discussed in the sample.

According to the research findings; participants are experiencing moderate loneliness. Again, when the calculated loneliness score is divided into dimensions; Eighty percent (79.2 percent) of the foreign students in the sample do not feel alone. Depending on the gender, loneliness levels do not differ significantly. However, according to the desire to live in a different country with a different culture, the level of loneliness is remarkable. In Turkey, about living in a different country outside of those with positive opinion, compared to a negative opinion on the matter stating that the level of solitude seems to be higher.

It was found by this research that 40.5 percent of foreign students in the sample had medium level and 58.5 percent had high intercultural communication anxiety. The results reveal that the purpose of education in intercultural communication concerns foreign students who come to Turkey. The results of the analysis emphasize that intercultural communication anxiety levels of men and women have close values. hot topics of the ministers live in a different country other than Turkey in the study; it was determined that the level of intercultural communication anxiety is higher than those who have negative attitudes in this regard.

The research reveals that the level of intercultural communication anxiety positively predicts loneliness score positively. As the level of intercultural communication anxiety increases; There is also an increase in the level of loneliness. When it is generally accepted that loneliness is a common problem of humanity (Russell et al., 1978; Gerson \& Perlman, 1979); Communication anxiety experienced by people from different cultures can have an impact on loneliness in this process. When communication anxiety is considered as the state of anxiety arising with the occurrence of erosion in people's relationships and thus the individual's stay away from his environment or withdrawal; this avoidance or disconnection may affect an individual's ability to establish and / or maintain close relationships. As such, communication anxiety should be expected to contribute to the problem of loneliness. In other words, the fact that communicating anxious people avoid communicating situations gradually constitutes the basis for loneliness (Zakahi \& Duran, 1982).

As a result of this fieldwork, Selcuk University in training to ongoing Designed to determine the nature of the relationship between loneliness levels and intercultural communication concerns of students from different countries, constitute one of the research very few in Turkey. Much more research is needed to understand the contribution of intercultural communication anxiety to the development and continuity of loneliness. Conducting similar studies in different regions of our country and on different samples; it will be important for the development of the literature and making comparisons. Future research can be applied to participants in cultural, ethnic and / or racially diverse business settings. In future researches, the relationship between intercultural communication anxiety and other variables such as cultivation, social cultural adaptation, ethnocentrism, happiness, subjective well-being, self-esteem and communication skills can be examined. 
Keywords: Intercultural Communication Apprehension, Loneliness, Foreign Student, Relationship

Öz: Kültürlerarası iletişim kaygısı, farklı kültür ya da gruplarla etkileşimde yaşanan korkuları ifade eden bir kavramdır. Farklı kültür ve alışkanlıklara sahip olan insanların ilk etkileşimleri sırasında, birbirleriyle ilgili bilgi eksiklikleri, beraberinde belirsizliğin artmasına neden olmakta; bu da etkileşimde bulunan kişilerin kaygı veya endişe duygularını tetiklemektedir. Söz konusu kişiler iletişim konusunda yüksek bir kaygı yaşadıklarında, başkalarıyla iletişimden kaçınma veya geri çekilme eğilimi gösterebilmektedir. İnsan ilişkilerinde yaşanan bu belirsizlikler ve kaygı hissi; kültürlerarası bağlamda etkili iletişimi tehlikeye sokmaktadır. Bu durum beraberinde özellikle yabancı uyruklu kişiler arasında kültürlerarası iletişim kaygısı ile yalnızlık arasında bir bağlantının olabileceğine işaret etmektedir. İşte bu araştırma kültürlerarası iletişim kaygısı ile yalnızlık arasındaki ilişkiyi mercek altına alınmayı amaçlamaktadır. Saha araştırması yönteminin kullanıldığı çalışmada veriler, 200 yabancı uyruklu öğrenciden yüz yüze anket tekniğiyle toplanmıştır. Araştırma bulguları, katılımcıların yarıdan fazlasının kültürlerarası iletişim kaygısı taşıdığına işaret etmektedir. Hem erkeklerin hem de kadınların kültürlerarası iletişim kaygı düzeyleri birbirlerine yakın değerler taşımaktadır. Türkiye dışında farklı bir ülkede yaşama konusuna sıcak bakanların kültürlerarası iletişim kaygı düzeyi; bu konuda olumsuz tutuma sahip olanlara nazaran daha yüksektir. Kültürlerarası iletişim kaygı düzeyi, yalnızlık puanının pozitif yönde anlamlı belirleyicisidir. Yabancı uyruklu üniversite öğrencilerinin kültürlerarası iletişim kaygı düzeyi arttıkça; yalnızlık düzeyinde de bir artış yaşanmaktadır.

Anahtar Kelimeler: Kültürlerarası İletişim Kaygısı, Yalnızlık, Yabancı Uyruklu Öğrenci, İlişki

\section{Giriş}

Kültürlerarası temasların bireysel ve toplumsal seviyede yoğunluk kazandığı günümüzde insanların, çeşitli gerekçelerle farklı kültürlere mensup bireylerle karşılaşmaları ve iletişime girmeleri kaçınılmaz olmuştur. Özellikle, küreselleşmeyle beraber bilişim, ulaşım ve iletişim teknolojileri gibi birçok faktörde meydana gelen gelişmeler; ülkeler arsındaki nüfus hareketliliğinin artması, ekonomi, siyaset, turizm ve eğitim gibi ç̧eşitli alanlarda farklı kültürlerin karşılaşmalarını hızlandırmış ve kültürlerarası etkileşimleri artmıştır. Kültürlerarası temasın yoğunlaşmasıyla paralel olarak uluslararası hareketlilikte de bir artış yaşanmıştır. Tüm bu gelişmelerin sonucunda, kültürlerarası iletişim kavramı üzerinde önemle durulması gereken bir konu haline gelmiştir. Genel bir tanımla kültürlerarası iletişim, farklı kültürel gruplara, alt kültürel arka alanlara, bilgi ve tecrübeye sahip kişiler arasındaki sembolik ve interaktif alışveriş sürecidir. Bir başka ifadeyle, aynı bölgede, ülkede, şehirde veya sokakta yaşayanların birbirleriyle olan ilişkilerinde ortaya çıkan karşıllklı etkileşimleridir (Öğ̈ü, 2018: 69; Yağbasan, 2016: 34).

Son yıllarda kültürlerarası farklılıkların artık iletişim ve etkileşim sürecindeki engel olarak görülmesinden ziyade; birer kaynak olduğu yönündeki inancın yaygınlık kazanmaya başladığı ileri sürülebilir. Şöyle ki, günümüzde dünya yönetiminde aktif rol alan küresel liderler de kültürel farklılıkların iyi yönetilmesi durumunda birer kaynak olarak görev yapacağına inanmaktadırlar (Bekiroğlu \& Balc1, 2014: 431-432). Gelinen nokta itibariyle kültürlerarası karşılaşmalarda kültürlerarası iletişim yeterliliğine dolayısıyla kültürlerarası duyarlılığa sahip olmak oldukça önem arz etmektedir. Kültürlerarası duyarlılık, etkileşimsel durumun bilişsel, duyuşsal ve davranışsal yönleriyle ilişkili olmasına rağmen, temelde duygularımızla ilgilidir. Yani kültürlerarası duyarlılık gerçekte duygularla ilişkili alana karşılık gelir. Kültürel farklılıklara ve farklı kültürlerden bireylerin düşüncelerine duyarlı olmayı ifade eder. İkinci olarak duygusal durumun temelini oluşturan bilişsel düzeye karşılık gelen farkındalık başka ifadeyle kültürlerarası iletişim yeterliliğinin bilişsel perspektifi, kişinin kendi özelliklerini ve başkalarının kültürlerini anlama yoluyla çevreyle ilgili kişisel düşüncenin değişmesi durumudur. Kültürlerarası iletişim yeterliliğinin davranışsal perspektifi olarak adlandırılan davranışsal yeterlilik, iletişimcinin iletişim kurarken bilişsel ve duygusal deneyimlerini dışa vurma veya ifade etme kapasitesidir. Yani bireylerin sözel ve sözel olmayan davranışlarını içeren iletişim becerileridir ve bu iki durum da davranışsal boyuta karşılık gelen 
kültürlerarası iletişim yeterliliğine ulaştırır (Chen, 1997: 5; Portalla \& Chen, 2010: 22; Balcı \& Öğüt, 2018: 499).

Kültürlerarası iletişim sürecinde, her toplum iletişim kurduğu diğer toplumdan farklıdır ve kendine has bazı genel eğilimlere sahiptir. Bu eğilimler, herhangi bir toplum içinde birtakım alışkanlıkların, umutların ve fikirlerin diğer alternatiflerden daha çok tercih edildiğini gösteren yönelimlerdir. Yani bireyin içinde yaşadığ 1 kültür tarafından oluşturulan bu yönelimler, bireyin yaşam şeklini, dünyaya bakış açısını, inançlarını, değerlerini ve etkileşim sürecindeki davranışlarını etkilemektedir. Bu farklı yönelimler farklı kültürden gelen kişilerin birbirleriyle kurdukları etkileşim evresinde karşıllıklı yanlış anlamaların yaşandığı bir evreye dönüşebilir. Hatta kültürel farklılıklardan dolayı kültürlerarası iletişim sürecinde kişiler zaman zaman birbirleriyle iletişime girme konusunda isteksizlik duyabilirler ve ya etkileşim sürecinde kaygı yaşayabilirler (Bozkaya \& Aydın, 2010: 31).

Kültürlerarası etkileşim sırasında birçok kişi, utangaç olma, gülünç olma veya reddedilme gibi olumsuz değerlendirme korkusundan kaynaklanan düşünce kaygısı ve buna bağlı olumsuz duyguları yaşar. Kültürlerarası etkileşimler sırasında yaşanan iletişim kaygısı, davranışsal sonuçları doğurur. Kayg1, insanları mümkün olduğunca çabuk etkileşimden kaçmaya ya da terk etmeye yönlendirecek ve yoğun duygular rahatsızlık, korku, kızgınlık, hatta öfke ve tiksinti gibi duygusal sonuçlar doğuracaktır. Tüm bireylerin üstesinden gelmek zorunda olduğu temel sorunlardan biri olarak kabul edilen kaygı, duygusal bir eşdeğerdir. Kaygı düzeyinin artması ya da azaltılması konusunda iyi bir yönetim, etkili iletişim sağlamasına yol açar. Yani kültürlerarası etkileşimde kayg1 düzeyi önemli rol oynamaktadır (Öğ̈̈t, 2018: 135-136).

Kültürlerarası iletişim kaygısı, insanların yabancı bir kültürden gelen ya da farklı bir geçmişe ve yaşam deneyimlerine sahip olan başka biriyle etkileşime girdiğinde duydukları korku veya endişe düzeyini ifade eder. Kültürlerarası karşılaşmalarda bireylerin kaygı düzeyi etkili iletişim kurulabilmesi açısından önem taşımaktadır. Bilinmeyen yeni durumlar ve yenilikler bireylerdeki kaygı̈ düzeyinin yükselmesine zemin hazırlar. Farklı durum ve farklılıklar eğer kültürlerin zenginliği olarak görülmezse ve iletişim kayg1 düzeyi iyi yönetilmezse, kültürlerarası durumlarda bireyler iletişime girmekten kaçınarak yalnızlaşmasına zemin hazırlayacaktır. Yani birey zorunlu bir yalnızlık deneyimi yaşamak zorunda kalacaktır.

\section{Kültürrlerarası İletişim Kaygısı}

Duygusal bir tepki olan kaygı, oluşacak durumlarla ilgili tedirginlik, gerginlik ve endişe duymaktır. Karşımızdaki kişinin nasıl davranacağını tahmin edememek belirsizliğe sebep olurken, kaygı ise ortaya çıkabilecek negatif sonuçlarla ilgili duyguları içerir. Gerçekte kaygı tüm insanların aşması gereken bir sorundur. Etkileşime katılan bireyler muhatapları hakkında bilgi sahibi oldukça belirsizlik ve kaygı azalmaktadır. Belirsizlik ve kaygı düzeyi etkin iletişim kurmak için önemlidir. Belirsizlik ve kaygı düzeyinin yüksek olduğu durumlarda istenilen iletişim kurulamaz. Bu durumda iletişime katılan bireyler muhataplarının gönderdiği mesajları doğru olarak anlayamaz ve yorumlayamazlar. Belirsizlik ve kaygı düzeyi istenilenden çok düşük olduğu zamanda da bireyler iletişime katılmaz. Tüm bu nedenlerden dolayı kültürlerarası iletişim yeterliliği alanında yapılan çalışmalardaki maksat belirsizliği ve kaygıya tamamen kaldırmak değildir (Kartarı, 2014: 241-242).

Farklı kültürel geçmişe sahip insanlarla gerçek veya beklenen etkileşim durumu bireylerde kaygıya yol açabilir (Lin \& Rancer, 2003: 64). Kültürlerarası iletişim kaygısı, bireylerin kültürel, etnik ve/veya 1rksal olarak farklı gruplara mensup kişi ya da kişilerle gerçek ve ya beklenen etkileşimle ilgili korku veya endişedir. Özetle, bireylerin, gerçek ve ya beklenen bir iletişimle bağlantılı korku ya da kaygı seviyesidir (Neuliep \& McCroskey, 1997: 145).

Kültürlerarası iletişim kaygı düzeyi yüksek olan bireyler, etnik veya kültürel olarak farklı gruba mensup kişilerle karşılaştıkları zaman kendilerini belirsiz bir durum içinde hissederler. Belirsiz olan durumlarda bireylerin kaygı düzeylerinin daha da artmasına sebep olur. Bir ortamın birey için 
belirsiz olması, bireyin yeni ve farklı bir durumla karşılaşması demektir.Böyle ortamlarda kişiler karşısındakiyle ilgili yeterli bilgiye sahip olamaması,onun davranışları,mesajı algılama ve yorumlama konusunda belirsizlik hissetmesi kaygı yaşamasına sebep olur (Bozkaya \& Aydın, 2010: 31-32).

Bireyler farklı kültürlerle karşılaştıklarında, diğer kültürlere mensup insanları yabancılar olarak görme eğilimindedirler. Yabancılar, farklı gruplara mensup bilinmeyen insanlardır. Farklı kültüre veya etnik gruba mensup insanlarla etkileşim kurmak, yüksek düzeyde yabancılık ve çok az aşinalık içermektedir. Bu gibi koşulların varlığı ise kültürlerarası iletişim kaygısı oluşturduğu ileri sürülebilir. Yenilik ve farklılıklar kaygının artışına yol açan iki önemli durumlardır. Farklı uyaranlar içeren yeni ve atipik durumlar bariz bir șekilde kaygı düzeyini artırabilir. Kültürlerarası iletișim ortamları ise potansiyel olarak yenilik ve farklılıklarla doludur. Gudykunst'e (1995) göre, etkili kültürlerarası iletişim, kısmen kayg1 ve belirsizliği yönetme kabiliyetine dayanmaktadır. Kayg1, bireyin diğer birey ya da bireylerle etkileşimi sırasında hissettiği endişe, sıkıntı ve korku durumu olarak tanımlanabilir. Kültürlerarası iletişim kaygısı yaşayan kişiler, farklı kültürlerden veya etnik gruplardan kişileri ilgilendiren iletişim durumlarıyla karşılaştığında, endişe, korku, huzursuzluk ve gerginlik yaşarlar (Olkun \& Ögüt, 2018: 516; Neuliep \& Ryan, 1998: 89).

İletişimdeki belirsizlik kaygıya yol açıyor. Farklı bir kültürden bir bireyle iletişimde belirsizlik, kültürlerarası iletişim kaygısı olarak bilinen özel bir endişe biçimine yol açar. Bilişsel kopukluk, hem fizyolojik hem de duygusal olarak görünen endişelere neden olan belirsizliğe yol açar. Böyle bir endişe artmış fizyolojik uyarılmaya, bedensel reaksiyonlara karşı aşırı duyarlılığa, görsel inceleme korkusuna, endişeyi açığa vurma korkusuna ve algılanan kontrol kaybına neden olabilir. Kültürlerarası iletişim sırasında bireylerin belirsizliği arttıkça kaygıları da artar. Kültürlerarası iletişim kaygısı arttıkça, bireyler bu etkileşimlere katılmaya daha az isteklidirler. Eğer Kültürlerarası iletişim kaygı seviyeleri azaltılabilirse, bireyin başka bir kültürle iletişim kurmaya istekli olması da artabilir (Fall et al., 2013: 414-415).

Özetlemek gerekirse, kültürlerarası iletişim kaygısı, insanların yabancı bir kültürden gelen ya da farklı bir geçmişe ve yaşam deneyimlerine sahip olan başka biriyle etkileşime girdiğinde duydukları korku veya endişe düzeyini ifade eder. Kültürlerarası karşılaşmalarda bireylerin kaygı düzeyi etkili iletişim kurulabilmesi açısından önem taşımaktadır. Kültürlerarası iletişim kaygısının insanlar üzerinde tanımlanan etkileri mevcutur. Bunlar, kültürel farklılıkların olumsuz algılanması ve kültürlerarası etkileşim durumlarında rahatsız edici davranış sergilenmesi gibi duygulardır. Daha spesifik olmak gerekirse, bu duygular, belirsizlik, hüsran, stres ve kavga eğilimi gibi duygular, ancak bunlarla sınırlı değildir (Quero, 2014: 14; Sathiensathidkun, 2015: 4).

\section{Yalnızlık}

Sosyal bir varlık olan insan, hayatını düzenli bir şekilde devam ettirebilmesi için diğer kişilerle birlikte olmak durumundadır. Kelime olarak başkalarından uzak olma manasına gelen yalnızlık, toplumda her insanın yaşamı süresince en az bir kez yaşadığı bir deneyimdir. Ancak bu deneyimin şiddeti kişiden kişiye göre değişiklik göstermektedir (Karakoç \& Taydaş, 2013: 36; Mercan vd., 2012: 215). Yalnızlığın tanımı konusunda ortak bir uzlaşı bulunmamaktadır. Peplau ve Perlman (1979: 101-102) yalnızlığı, "bir insanın sosyal ilişkiler ağının nitelik veya nicelik açısından önemli ölçüde eksik olduğu durumlarda meydana gelen tatsız bir deneyim"olarak tanımlamaktadır. Perlman ve Peplau'nun bu yalnızlık tanımı, yalnızlıkla ilgili üç ayırt edici önemli noktayı kapsamaktadır: Birincisi, yalnızlık, kişinin sosyal ilişkilerindeki eksikliklerden kaynaklanır, ikincisi, yalnızlık öznel bir fenomendir (her zaman sosyal izolasyonla aynı anlama gelmez, birey kalabalıklarda dahi kendini yalnız hissedebilir), üçüncüsü, yalnızlık tatsız ve üzücüdür (Perlman \& Peplau, 1981: 32). Bazı insanlar yalnızlık için diğerlerinden daha fazla risk altında olsalar da, toplumun hiçbir kesimi tamamen bağışı değildir. Yalnızlık tipik olarak rahatsız edici ve üzücü bir deneyimdir. Yalnızlık hem şiddetli hem de uzun sürerse, bir kişinin zihinsel sağlığını tehlikeye 
atabilir. Bu nedenle yalnızlık haklı olarak sosyal ve ruh sağlığı araştırmacıları tarafından araştırılan önemli konular arasında yerini almaktadır. Yalnızlık, bir insanın sosyal ilişkilerinin önemli bir şekilde eksik olduğunu gösteren acı verici bir deneyimdir (Perlman \& Peplau, 1984: 13-15).

Yalnızlık, evrensel duygusal ve psikolojik bir deneyimdir. Yalnızlık deneyimleri her zaman kötü bir durum olarak algılanmaz zaman zaman insanlar yalnız kalabilecekleri sessiz bir ortam ararlar. Belirli durumlarda ise insanlar konuşma ihtiyacı hissederken daha sonra bu şekilde davranmakla yanlış yaptıklarını düşünürler. Bazen de insanlar kimseyle konuşmasa bile başkalarıyla aynı ortamda bulunarak kendilerini daha rahat hissedebilirler. Bu sebeple insanların ihtiyaçları olduğu anlarda yanlarında birilerinin olması önemlidir. $O$ halde yalnızlık zorunlu bir durum değilse ve bireyin kendi seçimiyse güzel olabilir (Yaşar, 2007: 241). Örneğin, gerçekte olumsuz ve acı veren bir durum olan yalnızlı̆̆ın zamam zaman bireyler için olumlu gelişmeler için gereklidir.Şöyleki,yalnızlık aynı zamanda bireye daha derin bir kişisel farkındalık kazanma, yaratıcı olma zamanı ve kendini gerçekleştirme ve yaşamın anlamını keşfetme firsatı veren normal bir deneyim olarak görülebilir (Baş, 2010: 422).

Bir kişinin toplumsal yapı içerisinde, kendi kişisel ihtiyaçlarını önemli ölçüde karşılayamadığı durumlarda ortaya çıkan tatsız deneyim olan yalnızlığın oluşumuna zemin hazırlayan bazı önemli etkenler bulunmaktadır (Balcı \& Demir, 2018: 391; Çakır \& Çakır, 2011: 133). Olası yalnızlığın sayısız öncüleri vardır. Ancak yalnızlığın öncülerini hazırlayan ve hızlandıran faktörler olarak iki kategoride incelemek mümkündür: Hazırlayıcı faktörler, bireyin sosyal ilişkilerinin miktar ve kalitesini, bireyin özelliklerini (kişilik ve fiziksel özellikler gibi) ve belli bir durumun veya kültürün daha genel özelliklerini kapsar. Bu hazırlayıcı faktörlerin çoğu, bireyin başardığı veya arzu ettiği sosyal temas miktarının altında yatan değişkenlerdir. Çünkü bu hazırlayıcı faktörler aynı zamanda insanların, arzu ettiği veya başardığ 1 sosyal temas seviyelerini değiştirebilecek yaşam değişikliklerine nasıl tepki vereceğini belirler veya bu tepkileri sınırlandırır (Perlman \& Peplau, 1981: 37-38). Utangaçlık (sosyal etkileşimlerden kaçınma ve sosyal durumlara uygun şekilde katılamama eğilimi), öz saygı, benzerlik (ırk veya etnik köken, milliyet, yaş, bölge, vb.), sosyal beceri eksikliği, fiziksel çekicilik, demografik özellikler (cinsiyet, medeni durum, gelir, yaş) ve çocuklukta yaşananlar (anne ve babanın boşanması, ailenin çocukla ilişkilerinin çocuk tarafından anlama ve hatırlanma şekli) vb. özellikler farklı şekillerde yalnızlığı etkileyebilen ve yalnızlığı hazırlayıcı bireysel faktörlerdir. (Perlman \& Peplau, 1981: 41-44; Çakır \& Çakır, 2011: 133). Sonuç olarak çeşitli hazırlayıcı faktörler bir kişinin yalnızlık riskini artırabilir. Kişilik ve aşırı utangaçlık veya sosyal beceri eksikliği gibi davranışlardaki bireysel farklılıklar, tatmin edici sosyal ilişkiler oluşturma veya sürdürmeye engel olabilir böylece yalnızlık için zemin hazırlayabilir. Kültürel değerler ve normlar aynı zamanda bir kişinin yalnızlığa karşı savunmasını da etkileyebilir. (Perlman \& Peplau, 1998: 572). Hızlandırıcı/Yoğunlaştırıcı Faktörler, hızlandırıcı olaylar genel olarak bir insanın kazandığı sosyal ilişkilerde ve bir insanın istediği veya beklenen sosyal ilişkilerinde meydana gelen değişiklikler olarak sınıflandırılabilir. Burada önemli olan bu iki durum arasındaki uyumsuzluktur (Çakır \& Çakır, 2011: 133; Peplau \& Perlman, 1979: 102-103). Bir bireyin bir grup veya kuruluş içindeki konumu, grubun içinde ve dişındaki diğer insanlarla etkileşimini önemli ölçüde etkiler. Sonuç olarak, durumdaki değişiklikler yalnızlığa yol açabilir. Örneğin, işte terfi etmek, eski meslektaşlarla bağları zayıflatabilir ve yeni arkadaşlık ilişkileri kuruluncaya kadar yalnızlı yaratabilir (Perlman \& Peplau, 1981: 39).

Birçok sosyal bilimci yalnızlığın alabileceği çeşitli biçimler hakkında tahminde bulundular. Farklı yalnızlık türleri hakkında yapılan tartışmalar sonucu altta yatan üç boyut belirlenmiştir. Bunlar; Pozitiflik negatiflik (varoluşçu yalnızlık/yalnızlık kaygısı), kaynak (Sosyal ve duygusal yalnızlık) ve süresine (kroniklik) göre yalnızlık. Pozitiflik-Negatiflik Kriterine Göre Yalnızlık Türleri: Varoluşçu Yalnızlık ve Yalnızlık Kaygısı: Yalnızlığa varoluşçu bakış açısı ile bakan Moustakas'ın varoluşsal yalnızlık ve yalnızlık kaygısı arasında ayrım yaptı. Bu ayrımın altında yatan boyut yalnızlığın pozitiflik-negatiflik boyutudur. İnsanların temelde yalnız olduğu gerçeğini 
başlangıç noktası olarak alan varoluşçulara göre, yalnızlık, insanın yaşadığ yaşamın kaçınılmaz bir parçasıdır, kendi kendine yüzleşme dönemlerini içerir ve kendi kendine büyüme için bir yol sunar. Varoluşsal yalnızlık, "mükemmel yaratılışın" olumlu deneyimlerine yol açabilir. Buna karşılık, yalnızlık kaygısı, "insanla insan arasındaki temel yabancılaşmadan" kaynaklanan negatif bir deneyimdir. Ampirik kanıtlar, negatif duyguların yalnız insanların yaşamlarında baskın olduğunu göstermektedir. Yalnızlık dönemlerinin faydaları olmasına rağmen, yalnızlık konusundaki öznel deneyim nadiren olumlu düşünceler veya hisler ile birlikte olur (Perlman \& Peplau, 1984: 16-17; Çakır \& Çakır, 2011: 135). Kaynağına Göre Yalnızlık Türleri: Sosyal ve Duygusal Yalnızlı: Yalnızlık biçimlerini sınıflandırmanın ikinci yolu, sosyal eksiklik kaynağıyla ilgilidir. Weiss, duygusal yalnızlığı (kişisel, samimi bir ilişki ya da bağlanma olmamasına dayanarak) sosyal yalnızlıktan (sosyal "bağlantı" ya da topluluk duygusunun olmamasına dayanarak) ayırmıştır. Weiss göre duygusal yalnızlık, akut daha acı verici bir izolasyon şeklidir. Sosyal yalnızlık, bir sıkıntı duygusuyla birlikte reddedilen veya kabul edilemez bir hissin karışımı olarak yaşanır (Perlman \& Peplau, 1984: 17). Süresine Göre Yalnızlık Türleri: Geçici, Durumsal ve Kronik Yalnızlı: Zaman içinde yalnızlığın süresi yalnızlığın türlerini belirlemede önemli bir ölçüttür. Young yalnızlığı süreye göre üç tipe ayırmıştır. Bunlar geçici, durumsal ve kronik yalnızlık olarak belirlemiştir. Geçici veya günlük yalnızlık, kısa ve ara sıra yalnız ruh hallerini içerir. Bu deneyimler araştırmacılar veya klinisyenler için pek endişe verici olmamıştır. Durumsal veya geçici yalnızlık, boşanma, ölüm veya yeni bir şehre taşınmak gibi belirli bir değişiklik meydana gelinceye kadar tatmin edici ilişkileri olan insanları içerir. Durumsal yalnızlık çok üzücü bir deneyim olabilir. Kronik yalnızlık, bir kişinin iki veya daha fazla yıl boyunca tatmin edici sosyal ilişkilere sahip olmadığı durumlarda ortaya çıkan durumdur. Durumsal yalnızlık uzun süre devam ettiğinde kronikleşebilir (Perlman \& Peplau, 1984: 17).

\section{Kültürlerarası İletişim Kaygısı ve Yalnızlık}

Sosyal bir çevreye doğan kişi, bir taraftan fiziksel gelişimini devam ettirirken diğer taraftan da etrafindaki diğer kişilerle iletişim ve etkileşim oluşturarak yaşadığı toplumun bir üyesi olmak için çabalar. Başkaları ile bağlantı sağlama ve etkileşim kurma ihtiyacı, bireyin yapısal özelliklerinden dolayı hayatında önemli bir yer tutmaktadır. İnsan doğada tek başına yaşamını sürdüremez ve yaşamı boyunca içine doğduğu toplumu oluşturan kişilerle etkileşim içine girmek için uğraşır. Sosyal bir varlık olan insanın başkalarıyla iletişim kurmaya ve etkileşim sağlamaya tüm yaşamı boyunca ihtiyacı vardır. Günümüz modern dünyasında bireyler hızla artan nüfus ve kalabalıklaşan kentsel yaşamda yalnız bir insan haline dönüşmekte ve kendine yabancılaşmaktadır. Evrensel duygusal, psikolojik bir deneyim ve kişilerarası izolasyonun bir ürünü olarak yaşanan ve insanlardan uzak olma şeklinde görülen yalnızlık, bireyin etrafındaki kişileri tehdit edici olarak algılaması neticesinde, yüksek kaygı ve insanlardan uzaklaşma gibi bulgularla ortaya çıkmaktadır (Kılıç \& Alver, 2017: 117). Kayg1 insanların en temel duygularından biridir. Genel olarak kayg1, bireyin tehdit edici bir durum karşısında hissettiği huzursuzluk ve endişe durumu olarak tanımlamaktadır. Başka bir deyişle kaygı bireyin yalnızlığı ya da sevilmemesine uyum sağlamaya yönelik baskıyı hissetmesi olarak ifade edilmektedir (Karadağ \& Sölpük, 2018: 164).

Sosyal bir varlık olan insan diğer bireylerle iletişim kurması zorunlu bir ihtiyaçtır. İletişimdeki belirsizlik kaygıya yol açar. Kültürlerarası iletişimde kaygı artıkça bireyler etkileşim kurmakta daha az istekli olurlar. Bu durumda hoşgörünün azalmasına ve başka bir kültürden insanlara yönelik saygısızlığın artmasına neden olabilir (Fall et al., 2013: 414-415).

Kültürlerarası iletişim kaygısı, aynı zamanda sosyo-kültürel adaptasyonun negatif belirleyicisi konumundadır. Yabancı uyruklu kişilerin kültürler arası iletişim bağlamında kaygıları azaldıkça, sosyo-kültürel adaptasyonları kolaylaşmaktadır. Benzer şekilde kültürlerarası iletişim kaygısı azaldıkça, yaşam doyumunda bir artış yaşanmaktadır (Ata, 2019). Yine farklı ülkelere mensup arkadaşa sahip olma durumuna göre kültürlerarası iletişim kaygı düzeyi anlamlı olarak 
farklılaşmaktadır (Olkun \& Öğüt, 2018: 522). Aynı şekilde Yaşam doyum düzeyi ve kültürlerarası duyarlılık faktörlerinden etkileşimde kendine güven faktörü arasında anlamlı pozitif ilişki vardır. Kültürlerarası duyarlılığa sahip olmak yaşam doyum düzeyini önemli bir şekilde etkilemektedir (Öğ̈̈t, 2018).

Kültürlerarası iletişim kaygısı, insanların farklı bir kültüre ya da farklı bir geçmişe ve yaşam deneyimlerine sahip olan başka biriyle etkileşime girdiğinde duydukları korku veya endişe düzeyini ifade eder. Kültürlerarası karşılaşmalarda bireylerin yaşadığ 1 kaygı düzeyi etkili iletişim kurulabilmesi açısından önem taşımaktadır. Bilinmeyen yeni durumlar ve yenilikler bireylerdeki kaygı düzeyinin yükselmesine zemin hazırlar. Farklı durum ve farklılıklar eğer kültürlerin zenginliği olarak görülmezse ve iletişim kayg1 düzeyi iyi yönetilmezse, kültürlerarası durumlarda bireyler iletişime girmekten kaçınarak yalnızlaşmasına zemin hazırlayacaktır. Yani birey zorunlu bir yalnızlık deneyimi yaşamak zorunda kalacaktır.

Araştırmacılar, parasosyal etkileşim biçimindeki aracılı iletişim ile yalnızlığın azaltılabileceğini: yalnızlık ve iletişim kurmaya isteklilik ile bireyin iletişim kaygısı ve yalnızlık düzeyi arasında bağlantılar olduğunu göstermiştir. Karşılıklı bir ilişkide, depresyon ve yalnızlık kişilerarası iletişim problemleri yaratabilir veya derinleştirebilir (Heinz, 2018: 3).

İletişim sorunlarının, yalnızlığın gelişimine ve kalıcılığına katkısının anlaşılmasıyla onu önemli bir araştırma konusu haline getirmiştir. Yalnızlık ayrıca iletişim kaygısı ve iletişimsel yeterlilik ile de ilişkilendirilmiştir. Zakahi ve Duran (1985: 50) iletişim kaygısı ve yalnızlık ilişkisini ortaya koymak amacıyla gerçekleştirdikleri araştırmada, iletişim kaygısı ve yalnızlık arasında pozitif ve anlamlı bir ilişki olduğu sonucuna ulaşılmıştır. Downs ve arkadaşları (1987) ise, yaşlı erişkinlerde iletişim kaygısı ve yalnızlık duyguları arasındaki ilişkiyi ortaya koymak amacıyla yaptıkları çalışmada, daha yaşlı erişkinlerde iletişim kaygısı ile yalnızlık duyguları arasında pozitif bir ilişki olduğunu göstermiştir (Downs, Javidi \& Nussbaum, 1987: 38). Yine bir kayg1 türü olan sosyal etkileşim kaygısı da bireylerin farklı kültür ya da gruplarla etkileşimini önemli ölçüde etkilemektedir. Şöyle ki birey sosyal etkileşim kaygısına sahipse sosyal ortamlardan bulunmak istemeyecektir ve sosyal ortamlardan kaçınacaktır. Sosyal ortamlardan kaçan birey yalnızlaşacaktır. Bu bağlamda yapılan çalışmalarda sosyal etkileşim kaygısının yalnızlığı arttıran bir faktör olduğu vurgulanmaktadır. Buna göre sosyal ortamlardan ve kişilerarası ilişkilerden uzak durmaya çalışan bireylerin sıklıkla yalnız kaldığ 1 belirtilmektedir (Demir \& Kutlu, 2016: 196).

İşte yukarıdaki literatür taraması 1şığında, bu araştırmada aşağıda sıralanan sorulara cevap bulunmaya çalışılmaktadır:

$\checkmark$ A.S. 1. Katılımcıların kültürlerarası iletişim kaygı düzeyi nedir?

$\checkmark$ A.S. 2. Cinsiyete göre, kültürlerarası iletişim kaygı düzeyi anlamlı farklılık gösterir mi?

$\checkmark \boldsymbol{A}$.S. 3. Farklı bir kültüre sahip farklı bir ülkede yaşamağa isteğine göre, kültürlerarası iletişim kaygı düzeyi anlamlı farklılık gösterir mi?

$\checkmark$ A.S. 4. Katılımcıların yalnızlık düzeyi nedir?

$\checkmark$ A.S. 5. Farklı bir kültüre sahip farklı bir ülkede yaşamağa isteğine göre, yalnızlık düzeyi anlamlı farkl1lık gösterir mi?

$\checkmark \quad$ A.S. 6. Kültürlerarası iletişim kaygısı ile yalnızlık düzeyi arasında nasıl bir ilişki vardır?

\section{Yöntem}

$\mathrm{Bu}$ çalışmada yöntem olarak saha araştırması kullanılmıştır. Yabancı uyruklu öğrencilerin katılımıyla gerçekleşen saha araştırması yöntemiyle, yabancı uyruklu üniversite öğrencilerinin kültürlerarası iletişim kaygısı ile yalnızlık düzeyleri arasındaki ilişki ölçümlenmeye çalışılmıştır. 


\subsection{Araştırmanın Sorunu}

Geçmişle kıyaslandığında günümüz dünyasında daha fazla insan uluslararası düzeyde seyahat etmekte, farklı bir ülkede yaşamakta ve eğitim faaliyetlerine devam etmektedir. Bireyler için yabancı bir ülkede eğitim görme ve yaşama deneyimi, kendi ülkelerindeki hayata kıyasla alışkın olmadıkları bir çevreden dolayı, hem zihinsel hem de duygusal olarak zorlayıcı olabilmektedir. Söz konusu kişiler iletişim konusunda yüksek bir kaygı yaşadıklarında, başkalarıyla iletişimimden kaçınma veya geri çekilme eğilimi gösterebilmektedir (Gudykunst, 1995; Olkun \& Öğüt, 2018). İnsan ilişkilerinde yaşanan belirsizlikler ve kaygı hissi; genellikle kültürlerarası bağlamda etkili iletişimi tehlikeye sokmaktadır (Kim, 1988; Gudykunst, 2005; Kassing, 1997). Bu durum beraberinde özellikle yabancı uyruklu kişiler arasında, kültürlerarası iletişim kaygısı ile yalnızlık arasında bir bağlantının olabileceğine de işaret etmektedir.

\subsection{Araştırmanın Uygulanması ve Örneklem}

Araştırmanın evreni Konya merkezde ikamet eden ve Selçuk Üniversitesi'nde eğitim alan yabancı uyruklu öğrencilerden oluşmaktadır. Örneklemin belirlenmesinde basit tesadüfi örneklem alma tekniği uygulanmış; 235 öğrenciyle yüz yüze görüşülerek veriler toplanmıştır. Ön inceleme sonucunda 200 anket analiz için uygun görülmüsşür. Anketlerin geri dönüşüm oranı yüzde 85,1'dir.

Araştırmaya Senegal, Yemen, Endonezya, Kırgızistan, Kazakistan, Afganistan, Suriye, Uganda, Burundi, Etiyopya, Hindistan, Siera Leone, Makedonya, Zimbabve, Çad, Kenya, Bangladeş, Güney Afrika, Zambiya, Vietnam, Tacikistan, Irak, Tayland, Moritanya, Filipinler, Mısır, Fildişi Sahili, Sudan, Tanzanya, İran, Gambiya, Kongo, Ürdün, Somali, Gine, Cezayir, Arnavut, Çin, Azerbaycan, Kolumbiya, Kosova, Filistin, Nijerya, Özbekistan, Çeçenistan, Türkmenistan, Tunus, Malezya, Eritre, Lübnan, Rusya, Sırbistan, Fas, Makedonya, Ukrayna, Moğolistan, Gürcistan, Madagaskar, Libya, Mali, Angola ve Burkino Faso'dan öğrenciler katılmaktadır.

Katılımcıların yüzde 50'si erkek ve yine yüzde 50'si kadınlardan ibarettir. Oranlar, ankete katılanların cinsiyetleri açısından karşılaştırma yapmaya elverişlidir.

Yaş dağılımının betimleyici istatistikleri incelendiğinde ise; en düşük 17, en yüksek 34 yaşındaki katılımcılarla görüşüldügü ortaya çıkmaktadır. Ankete katılanların yaş ortalaması 22,91; dağılımın standart sapması ise 3,37'dir.

Araştırma sorularına cevap veren yabancı uyruklu öğrencilerin yüzde 89,5 gibi büyük bir kısmı yurtta kaldığını ifade ederken; yüzde 6'sı ailesiyle ve yüzde 4,5'i arkadaşlarla ikamet ettiğini dile getirmektedir.

Katılımcıların yüzde 86,5'i Müslüman, yüzde 13,5 'i ise diğer dinlere mensuptur. Diğer dinlere bağlı olanlar arasında Hıristiyanların (22 kişi, yüzde 11) ağırlığı bulunmaktadır.

Yabancı uyruklu öğrencilerin yüzde 62 gibi önemli bir bölümü, Türkiye dışında farklı bir ülkede bulunduğu ifade ederken, yüzde 38'si Türkiye ile birlikte yabancı ülke deneyimini yaşadığını vurgulamaktadır.

Bu soruyla bağlantılı olarak katılımcıların yüzde 83'ü farklı kültüre sahip farklı bir ülkede yaşamaya sıcak bakarken; yüzde 17'si bu konuda katı tutum sergilemektedir.

Örneklemde yer alan öğrencilerin Türkiye'de kalma sürelerinin betimleyici istatistikleri mercek altına alındığında; en düşük 1, en yüksek 9 yıldır ülkemizde bulunan katılımcılardan cevap alındığı dikkat çekmektedir. Ankete katılanların Türkiye'de kalma sürelerinin ortalaması 2,76; dağılımın standart sapması ise 1,84 'tür.

Bir başka noktada yabanc1 uyruklu üniversite öğrencilerinin yüzde 5'i sosyal medyada farklı kültürlerden insanlarla hiç iletişim kurmadığını vurgularken; yüzde 22,5 'i nadiren, yüzde 35,5 'i arasıra, yüzde 22 'si çoğu zaman ve yüzde 15 'i her zaman iletişim halinde olduğunu belirtmektedir. 


\subsection{Veri Toplama Araçları}

Çalışmanın uygulama bölümü için elde edilen veriler, 48 sorudan oluşan soru formunun katılımcılar tarafından verilen cevaplarından alınmıştır. Aşağıdaki anket formunda yer alan ölçeklerle ilgili tanıtıcı bilgilere yer verilmektedir.

UCLA Yalnızlık Ölçeği (UCLA Loneliness Scale): UCLA Yalnızlık Ölçeği orijinal olarak Russell, Peplau ve Ferguson (1978) tarafindan geliştirilmiş; daha sonra Russell, Peplau Cutrona (1980) tarafından yeniden düzenlenmiştir. Katılımcıların yalnızlık düzeylerini tespit etmeye yönelik oluşturulan ölçek, 10 maddesi olumlu (anlamsal olarak yalnızlık içermeyen), 10 maddesi de olumsuz (anlamsal olarak yalnızlık içeren) olmak üzere, 20 maddeden oluşan, 4'lü (1= Hiçbir Zaman, 4= Her Zaman) Likert tipi bir ölçektir (Duy, 2003: 90). Ölçekten alınabilecek en yüksek puan 80, en düşük puan 20'dir. Puan arttıkça yalnızlık düzeyi artmaktadır (Ağırman vd., 2017: 236). Bu araştırmada yalnızlık düzeyi kesme puanı $67(58,60 \pm 8,46)$ olarak hesaplanmıştır. Söz konusu puana göre 20- 67 puan "yalnızlık hissetmiyor", 68-80 puan "yalnızlık hissediyor" şeklinde değerlendirilmiştir (Benzer bir çalışma için bkz.; Softa vd., 2015, Balcı ve Demir, 2018). Ölçeğin Türkiye'deki geçerlik ve güvenirlik çalışmaları Demir (1989) tarafından gerçekleştirilmiştir. Demir (1989), ölçeğin Türkçe'ye uyarlamasını yapmış ve ölçeğin güvenirliği için yapılan çalışmada Cronbach Alfa Katsayısı ,96 bulunmuştur. Bu çalışmada ise Cronbach's $\alpha=, 91$ olarak hesaplanmıştır.

Kültürlerarası İletişim Kaygısı Ölçeği (Intercultural Communication ApprehensionPRICA): Araştırma kapsamında yararlanılan bu ölçek; Neuliep ve McCroskey (1997) tarafindan geliştirilen ve 14 maddeden oluşan bir yapıya sahiptir. Ölçek, bireylerin iletişim kaygılarını kültürlerarası bağlamda ölçmeye yönelik dizayn edilmiş olup; 5 Likert tipindedir ( $5=$ Kesinlikle katıliyorum, 4= Katıliyorum, 3= Kararsizım, 2= Katılmıyorum, $1=$ Kesinlikle katılmıyorum). Kültürlerarası İletişim Kaygısı (Intercultural Communication Apprehension) ölçeğinde yer alan 14 maddenin 7'sinin negatif $(2,4,6,8,11,13,14)$; diğer 7'sinin ise pozitif $(1,3,5,7,9,10,12)$ anlama sahip olduğu dikkat çekmektedir. Ölçeğin Türkçe güvenilirlik ve geçerlilik çalışması Ay ve arkadaşları (2018) tarafından yürütülmüştür. Yazarlar Kültürlerarası İletişim Kaygısı Ölçeği'nin yapı geçerliliğini belirlemek için varimax rotasyonu ile temel bileşenler analizi kullanılarak faktör analizi yapmışlar ve analiz sonucunda; kayg yaşayan ve yaşamayan olmak üzere iki alt boyut ortaya çıkmıştır (Ay vd., 2018). Neuliep ve McCroskey (1997) ölçeğin güvenilirlik katsayısını ,88 olarak tespit ederken; Türkiye'deki bazı araştırmalarda (Bozkaya \& Aydın, 2010; Çakıcı vd., 2017; Ay vd., 2018; Olkun \& Öğüt, 2018) ölçeğin güvenilirliği genel olarak ,80 üzerinde rapor edilmiştir. Bu çalışmada ise Cronbach's $\alpha=, 78$ olarak hesaplanmıştır.

Kişisel Bilgi Formu: Anket formunun bu kısımda, katılımcıların yaş, cinsiyet, ikamet etme biçimi ve din gibi sosyo-demografik bilgilerin yanı sıra; katılımcıların farklı bir ülkede bulunma durumu ve isteği, Türkiye' de kalma süresi ve sosyal medyada farklı kültürlerden insanlarla iletişim kurar sıklığını tespit etmeye yönelik sorular bulunmaktadır.

\subsection{Verilerin Analizi ve Kullanılan Testler}

Saha araştırması 15-30 Mayıs 2019 tarihinde, katılımcılarla yüz yüze görüşme yoluyla gerçekleştirilmiştir. Elde edilen veriler, istatistik programı kullanılarak, bilgisayar ortamında işlenmiştir. Araştırma kapsamında kullanılan Kültürlerarası İletişim Kaygıs1 (Skewness:-,722; Kurtosis: 1,148) ile Yalnızlık (Skewness: -,482; Kurtosis: -,028) ölçekleri için elde edilen Skewness (Çarpıklık) ve Kurtosis (Basıklık) değerleri $-2,0$ ile $+2,0$ arasında yer aldığından; verilerin normal dağılım gösterdiği ortaya çıkmaktadır (George \& Mallery, 2010). Dolayısıyla, verilerin analizinde parametrik testler kullanılmıştır. Verilerin analizinde sırasıyla; örneklemdeki kişilerin demografik özelliklerini saptamak amaciyla Frekans Analizi uygulanmıştır. Kültürlerarası iletişim kaygısı alt boyutlarını tespit etmek için Keşfedici Faktör Analizinden yararlanılmıştır. Kültürlerarası iletişim kaygısı ve yalnızlık düzeylerinin cinsiyete göre farklılaşıp farklılaşmadığını belirlemek amacıyla Bağımsız Örneklem T-Testi'ne başvurulmuştur. Katılımcıların kültürlerarası iletişim kaygı 
düzeylerinin yalnızlık düzeyini yordayıp yordamadığını ortaya koymak adına Doğrusal Regresyon Analizi esas alınmıştır. Aynı zamanda kültürlerarası iletişim kaygı düzeyi ile yalnızlık düzeyi arasındaki ilişkinin düzeyi ve yönünü belirlemek amacıyla da Korelasyon Analizi tercih edilmiştir.

\section{Bulgular ve Yorum}

Aşağıdaki bölümde öncelikle olarak araştırma sorulara cevap veren yabancı uyruklu öğrencilerin kültürlerarası kaygı ve yalnızlık düzeylerinin betimleyici istatistikleri verilmekte; daha sonra iki değişken arasında ilişki incelenmektedir.

\subsection{Yalnızlık Düzeyi}

$\mathrm{Bu}$ araştırma kapsamında UCLA Yalnızlık Ölçeğinde maddelere verdikleri cevap bakımından yabancı uyruklu öğrencilerin elde ettikleri en az puan 30, en çok puan 78 'dir.

Tablo 1: Katılımcıların Yalnızlık Düzeyinin Betimleyici İstatistikleri

\begin{tabular}{cccccc}
\hline & $\mathbf{N}$ & Min. & Max. & $\overline{\mathbf{X}}$ & SD \\
\hline Yalnızlık Düzeyi & 200 & 30 & 78 & 58,60 & 8,46 \\
\hline
\end{tabular}

Tablo 1'de örneklemdeki öğrencilerin yalnızlık düzeyi puanı ortalamasının 58,60 olduğu ortaya çıkmaktadır. Diğer bir ifadeyle araştırma sorularına cevap verenler orta düzey yalnızlık yaşamaktadırlar. Yine hesaplanan yalnızlık puanı boyutlara ayrıldığında; örneklemdeki yabancı uyruklu öğrencilerin yüzde 79,2'si kendisini yalnız hissetmezken (30-67 puan); yüzde 20,8'i yalnızlık hissi (68-80 puan) yaşamaktadır.

Tablo 2: Cinsiyete Göre Yalnızlık Düzeyindeki Farklılık

\begin{tabular}{cccccc}
\hline & Cinsiyet & $\mathbf{N}$ & $\overline{\mathbf{x}}$ & t-value & Sig. \\
\hline \multirow{2}{*}{ Yalnızlık Düzeyi } & Erkek & 100 & 59,14 & \multirow{2}{*}{, 893} & \multirow{2}{*}{, 373} \\
\hline
\end{tabular}

Katılımcıların cinsiyetine göre yalnızlık düzeyleri anlamlı farklılık taşımamaktadır $(\mathrm{t}=, 893$; $\mathrm{p}>$,05). Betimleyici istatistik sonuçları, hem erkeklerin $(\bar{X}=59,14)$ hem de kadınların $(\bar{X}=58,07)$ yalnızlık düzeylerinin birbirlerine yakın olduğunu göstermektedir.

Bir başka noktada farklı bir kültüre sahip farklı bir ülkede yaşamağa isteğine göre ise yalnızlık düzeyi anlamlı farklılık göstermektedir $(\mathrm{t}=2,14 ; \mathrm{p}<, 05)$. Türkiye'de dışında farklı bir ülkede yaşama konusunda olumlu kanaate sahip olanların $(\overline{\mathrm{X}}=59,18)$, bu konuda olumsuz görüş bildirenlere $(\overline{\mathrm{X}}=55,79)$ nazaran yalnızlık düzeyi daha yüksektir.

\subsection{Kültürlerarası İletişim Kaygı Düzeyi ve Boyutları}

Kültürlerarası İletişim Kaygı Ölçeğinde 14 maddeye verdikleri puan açısından katılımcıların sahip oldukları en az puan 30, en çok puan 78'dir. 
Tablo 3: Katılımcıların Kültürlerarası İletișim Kaygı Düzeyinin Betimleyici İstatistikleri

\begin{tabular}{cccccc}
\hline & $\mathbf{N}$ & Min. & Max. & $\overline{\mathbf{X}}$ & SD \\
\hline Kültürlerarası İletişim Kaygı Düzeyi & 200 & 26 & 69 & 53,37 & 7,29 \\
\hline
\end{tabular}

Tablo 3'de örneklemdeki öğrencilerin kültürlerarası iletişim kayg1 düzeyi puanı ortalamasının 53,37 olduğu ortaya çıkmaktadır. Bilindiği gibi ölçeğin toplam puanı 14 ile 70 arasında değişmektedir. 32 puanın altındaki toplam puan, kültürlerarası iletişim kaygısının düşük olduğunu, 52 puanın üzerindeki puan ise kültürlerarası iletişim kaygısının daha yüksek olduğunu göstermektedir. 32 ile 52 arasında bir puan, orta düzeyde kültürlerarası iletişim anlayışını ortaya koymaktadır (Ay vd., 2018: 1640). Bu haliyle hesaplanan kültürlerarası iletişim kayg1 puanı boyutlara ayrıldığında; örneklemdeki yabancı uyruklu öğrencilerin yüzde 1'i düşük (14-31 puan), yüzde 40,5 'i orta düzey (32-52 puan) ve yüzde 58,5 'i yüksek (53-70 puan) kültürlerarası iletişim kaygısı taşımaktadır.

Tablo 4: Cinsiyete Göre Kültürlerarası İletişim Kayg1 Düzeyindeki Farklılık

\begin{tabular}{lccccc}
\hline & Cinsiyet & $\mathbf{N}$ & $\overline{\mathbf{X}}$ & \multirow{2}{*}{ t-value } & \multirow{2}{*}{ Sig. } \\
\hline \multirow{2}{*}{ Külttürlerarası İletişim Kaygı Düzeyi } & Erkek & 100 & 53,89 & \multirow{2}{*}{, 998} & \multirow{2}{*}{, 320} \\
& Kadın & 100 & 52,86 & \\
\hline
\end{tabular}

Katılımcıların cinsiyetine göre kültürlerarası iletişim kaygı düzeyleri anlamlı farklılık göstermemektedir ( $\mathrm{t}=, 998 ; \mathrm{p}>, 05)$. Betimleyici istatistik sonuçlarına bakıldığında, hem erkeklerin $(\overline{\mathrm{X}}=53,89)$ hem de kadınların $(\overline{\mathrm{X}}=52,86)$ kültürlerarası iletişim kaygı düzeylerinin birbirlerine yakın değerler taşıdığı ortaya çıkmaktadır. Alanyazındaki farklı bir çalışmada Bozkaya ve Aydın (2010: 35) da benzer bulgular ortaya koymuşlardır.

Ancak farklı bir kültüre sahip farklı bir ülkede yaşamağa isteğine göre ise kültürlerarası iletişim kaygı düzeyi anlamlı farklılık taşımaktadır $(\mathrm{t}=3,83 ; \mathrm{p}<, 001)$. Türkiye'de dişında farklı bir ülkede yaşama konusuna sicak bakanların $(\overline{\mathrm{X}}=54,24)$; bu konuda olumsuz tutuma sahip olanlara $(\overline{\mathrm{X}}=$ 49,14) göre kültürlerarası iletişim kaygı düzeyi daha yüksektir.

Yine bu araştırma kapsamında katılımcıların kültürlerarası iletişim kaygısı alt boyutlarını belirlemek üzere 14 madde faktör analizine tabi tutulmuş; öz değer (eigenvalue) ve yamaç eğrisi grafiği (screeplot) incelemesi sonucunda 2 faktör grubunun ele alınabileceği anlaşılmıştır. Ölçek sıralamasında yer alan 12 ve 13. maddeler gerekli yükleme değerine sahip olmadıkları için analiz dışında bırakılmıştır. Ölçekte yer alan ifadelerin faktör yükleme değerleri Tablo 5 'te ortaya konulmaktadır. 
Tablo 5: Kültürlerarası İletişim Kaygısı Alt Boyutlarını Belirlemeye Yönelik Faktör Analizi Sonuçları (Principal Component Analysis, Varimax Rotation, N=200)

Kültürlerarası İletişim Kaygısı Alt Boyutları

Faktör

Yükleme

1. Faktör: Kaygı Yaşayan

8. Genellikle farklı kültürden biriyle görüşmelerde çok sinirli ve gerginim

2. Farklı kültürlerden insanlarla etkileşime girerken sinirli ve gerginim

14. Farklı kültürlerden insanlarla iletişim kurmak beni rahatsız ediyor

6. Farklı kültürden biriyle görüşme yaparken çok sinirli (gergin) olurum

11. Farklı kültürden biriyle konuşmaktan korkuyorum

4. Farklı kültürlerden insanlarla grup tartışmasına katılmak beni sinirlendiriyor

\section{Faktör: Kaygı Yaşamayan}

1. Genellikle farklı kültürden biriyle görüşmelerde çok sakin ve rahatım

5. Farklı kültüre mensup insanlarla etkileşim kurarken sakin ve rahatım

9. Genel olarak, farklı kültürlerden insanlarla etkileşimde rahatım

10. Farklı kültürden biriyle konuşurken, kendimi çok rahat hissediyorum

7. Farklı kültürden biriyle konuşmaktan korkmuyorum

3. Farklı kültüre mensup kişilerle grup tartışmalarına katılmaktan hoşlanıyorum

Faktör gruplarının sınıflandırılma ve değerlendirilmesinde Varimax rotasyonlu tablo dikkate alınmıştır. Faktör analizinde incelenen maddelerin özdeğeri 1'den daha büyük ve minimum yükleme büyüklüğü 0,40 'dır.

Tablo 6: Kültürlerarası İletişim Kaygısı Alt Boyutlarının Özdeğeri, Açıklanan Varyansları ve Güvenilirlik Katsayıları

\begin{tabular}{lccc}
\hline Alt Boyutlar & Özdeğer & $\begin{array}{c}\text { Açılkanan Varyans } \\
(\boldsymbol{\%})\end{array}$ & $\begin{array}{c}\text { Cronbach's } \\
\text { Alpha }(\boldsymbol{\alpha})\end{array}$ \\
\hline Kaygı Yaşayan & 4,35 & 25,23 &, 78 \\
\hline Kaygı Yaşamayan & 1,29 & 21,89 &, 70 \\
\hline TOPLAM & & 47,12 &, 77 \\
\hline
\end{tabular}

KMO Measure of SamplingAdequacy: ,826; Barlett's Test of Sphericity: $X^{2}=725,28 ; \mathrm{df}=66 ; \mathrm{p}=, 000$

Faktör analizine dâhil edilen 14 maddenin güvenilirlik katsayısı (Cronbach's $\alpha=, 77$ ) oldukça tatmin edicidir (Bkz., Yıldız \& Uzunsakal, 2018: 19). Analiz sonucunda ortaya konan iki alt boyut, kültürlerarası iletişim kaygısı açısından toplam varyansın yüzde 47,12'sini açıklama kapasitesi sahiptir.

\subsection{Kültürlerarası İletişim Kaygısı ile Yalnızlık Arasındaki İlişki}

Araştırmanın bu aşamasında öncelikle yabancı uyruklu öğrencilerin, kültürlerarası iletişim kaygı düzeyinin yalnızlık düzeyini açıklama gücü, Doğrusal Regresyon Analizi ile incelenmiş ve elde edilen sonuçlar Tablo 7'de gösterilmiştir. 
Tablo 7: Yalnızlık Düzeyi Puanının, Kültürlerarası Kaygı Düzeyi Tarafından Yordanmasına İlişkin Doğrusal Regresyon Analizi Sonuçları

\begin{tabular}{lcccc}
\hline & B & Beta $(\boldsymbol{\beta})$ & t & Sig. \\
\hline (Sabit) Yalnızlık Düzeyi (İndeks) & 38,704 & & 9,20 &, $\mathbf{0 0 0}$ \\
\hline Kültürlerarası İletişim Kaygısı (İndeks) &, 373 &, 322 & 4,77 &, $\mathbf{0 0 0}$ \\
\hline $\mathrm{R}^{2}=, 103$; Adjusted $\mathrm{R}^{2}=, 099$ & & & $\mathrm{~F}=22,82 ; \mathrm{df}=1 ; \mathrm{p}=, 000$ \\
\hline
\end{tabular}

Kültürlerarası iletişim kaygı düzeyinin bağımsız değişken olarak denkleme sokulması sonucu regresyon katsayısı ,373 olarak tespit edilmiştir. Kültürlerarası iletişim kaygısı, yalnızlık düzeyi puanındaki varyansın yaklaşık yüzde 10'unu açıklama kapasitesine sahiptir. Yalnızlık düzeyini, kültürlerarası iletişim kaygı düzeyinin yordayıp yordamadığına ilişkin $\boldsymbol{\beta}$ ve $\mathbf{t}$ değerleri incelendiğinde; kültürlerarası iletişim kaygı düzeyinin $(\beta=, 322 ; \mathrm{p}<, 001)$ yalnızlık puanını pozitif yönde anlamlı biçimde yordadığı ortaya çıkmaktadır.

Tablo 8. Kültürlerarası İletişim Kaygısı ile Yalnızlık Arasındaki İlişki (Pearson $r$ )

\begin{tabular}{lc}
\hline Kültürlerarası İletişim Kaygısı (İndeks) & Yalnızlık (İndeks) \\
\hline
\end{tabular}

Not: **Correlation is significant at the 0.01 level (2-tailed).

Korelasyon Analizi bulguları da iki değişken arasında pozitif yönde, zayıf düzey anlamlı ilişkinin varlığına işaret etmektedir $(r=, 322 ; \mathrm{p}<, 01)$. Bir başka anlatımla, kültürlerarası iletişim kaygı düzeyi arttıkça; yalnızlık düzeyinde de bir artış yaşanmaktadır.

\section{Tartışma ve Sonuç}

Küreselleşmeyle birlikte bilişim teknolojilerindeki gelişmeler, kültürlerarası kişiler ve etkileşimler için fırsatları artırmıştır. Farklı kültüre sahip bireyler ilk karşılaşmalarında birbirleri hakkında yeterli bilgiye sahip olmadıklarında belirsizliğin artmasına sebep olacaktır. Bu da iletişimde bulunan bireylerin kaygı ve endişe durumlarını artıracaktır. Etkileşimde bulunan bireyler iletişime girme konusunda yüksek bir kaygı taşıdıklarında, başkalarıyla iletişimden kaçınmakta ya da geri çekilme eğilimi gösterebilmektedir. Kişilerarası ilişkilerde yaşanan bu belirsizlikler ve kaygı durumu; kültürlerarası bağlamda etkili iletişimi tehlikeye sokmaktadır. Tüm bu gelişmeler sonucunda insanların farklı bir kültürle etkili iletişim kurması, kültürlerarası durumlarda bireylerin yabancı hissetmemesi ve oluşabilecek iletişim çatışmalarının önüne geçilmesi için bireylerin kültürlerarası iletişim kaygı düzeyinin bilinmesi önemlidir. Ayrıca Bireylerin kültürlerarası iletişim kaygı seviyeleri azaltılabilirse, farklı bir kültürle iletişim kurma isteğinin artırılmasının yanında onların yalnızlık hissetmelerinin önüne de geçilecektir. Yabancı uyruklu öğrencilerin kültürlerarası iletişim kaygısı ile yalnızlık düzeyleri arasında bir bağlantının olup olmadığının tespiti için yapılan bu çalışmada Selçuk üniversitesinde eğitim gören yabancı uyruklu öğrenciler örnekleminde ele alınmıştır.

Araştırma bulgularına göre; katılımcılar orta düzey yalnızlık yaşamaktadırlar. Yine hesaplanan yalnızlık puanı boyutlara ayrıldığında; örneklemdeki yabancı uyruklu öğrencilerin yüzde seksene yakın bir kısmı (yüzde 79,2) kendisini yalnız hissetmemektedir. Cinsiyetine göre yalnızlık 
düzeyleri anlamlı farkl11ık göstermemektedir. Ancak farklı bir kültüre sahip farklı bir ülkede yaşamağa isteğine göre ise yalnızlık düzeyi anlamlı farklılık gösterdiği dikkat çekmektedir. Türkiye'de dışında farklı bir ülkede yaşama konusunda olumlu kanaate sahip olanların, bu konuda olumsuz görüş bildirenlere nazaran yalnızlık düzeyi daha yüksek olduğu görülmektedir.

Örneklemdeki yabanc1 uyruklu üniversite öğrencilerinin yüzde 40,5'inin orta düzey ve yüzde 58,5'inin ise yüksek kültürlerarası iletişim kaygısına sahip olduğu bu araştırma ile bulgulanmıştır. Sonuçlar eğitim amacıyla Türkiye'ye gelen yabancı uyruklu üniversite öğrencilerinde kültürlerarası iletişim kaygısının bulunduğunu ortaya koymaktadır. Analiz sonuçları erkeklerin ve kadınların kültürleraras1 iletişim kayg1 düzeylerinin birbirlerine yakın değerler sahip olduğuna vurgu yapmaktadır. Araştırmada Türkiye'de dışında farklı bir ülkede yaşama konusuna sıcak bakanların; bu konuda olumsuz tutum taşıyanlara nazaran kültürlerarası iletişim kaygı düzeyinin daha yüksek olduğu belirlenmiştir.

Araştırmada kültürlerarası iletişim kaygı düzeyinin, yalnızlık puanını pozitif yönde anlamlı biçimde yordadığı ortaya çıkmaktadır. Kültürlerarası iletişim kaygı düzeyi arttıkça; yalnızlık düzeyinde de bir artış yaşanmaktadır. Yalnızlığın insanlığın ortak bir problemi olduğu genel olarak kabul edildiğinde (Russell et al., 1978; Gerson \& Perlman, 1979); farklı kültürlerden insanların yaşadıkları iletişim kaygıları, bu süreçte yalnızlığı artırıcı bir etki oluşturabilmektedir. İletişim kaygısı, insanların ilişkilerinde erezyonlanın yaşanmasıyla birlikte, endişe durumunun ortaya çıkması ve böylece bireyin çevresinden uzak durması veya geri çekilmesi hali olarak değerlendirildiğinde; bu kaçınma veya iletişimden kopma, bireyin yakın ilişkiler kurma ve /veya sürdürme yeteneğini etkileyebilmektedir. $\mathrm{Bu}$ haliyle iletişim kaygısının yalnızlık sorununa katkıda bulunması beklenmelidir. Diğer bir ifadeyle iletişimsel açıdan endişeli kişilerin iletişim içeren durumlardan giderek kaçınması, yalnızlık için gerekli zemini oluşturmaktadır (Zakahi \& Duran, 1982).

Sonuç olarak bu saha çalışması, Selçuk Üniversitesi'nde eğitimlerine devam eden farklı ülkelerden öğrencilerin kültürlerarası iletişim kaygısı ile yalnızlık düzeyleri arasındaki ilişkinin doğasını belirlemek amacıyla dizayn edilen, Türkiye'deki çok az sayıdaki araştırmadan birisini oluşturmaktadır. Kültürlerarası iletişim kaygısının, yalnızlığın gelişimine ve sürekliliğine olan katkısını anlamak için çok daha fazla araştırmaya ihtiyaç bulunmaktadır. Ülkemizin farklı bölgelerinde ve farklı örneklemler üzerinde benzer çalışmalarının yapılması; literatürün gelişmesi ve karşılaştırmalar yapmak bakımından önem arz edecektir. Gelecekteki araştırmalar, kültürel, etnik ve/ veya ırksal olarak farklı iş ortamlarındaki katılımcılara uygulanabilir. Yine gelecekteki araştırmalarda kültürlerarası iletişim kaygısı ile kültürleşme, sosyal kültürel adaptasyon, etnosentrizm, mutluluk, öznel iyi oluş, benlik saygısı ve iletişim becerisi gibi diğer değişkenler arasındaki ilişki mercek altına alınabilir.

\section{Kaynakça}

Ay, E., Kavuran, E., \& Turkoglu, N. (2018). Intercultural Communication Apprehension Scale (PRICA): Validity and Reliability Study in Turkish. International Journal of Caring Sciences, 11 (3), 1638-1646.

Ağırman, E., Gençer, M.-Z., Arıca, S., Kaya, E., \& Eğici, M.-T. (2017). "Huzurevinde, Evde Ailesiyle ve Yalnız Yaşayan Yaşlı Bireylerde Depresyon, Yalnızlık Hissi Düzeylerinin Karşılaştırılması". Journal of Contemporary Medicine, 7 (3), 234-240.

Ata, F. (2019). Kültürlerarası İletişim Kaygısı İle Sosyo- Kültürel Adaptasyon Ve Yaşam Doyumu Arasındaki İlişki: Hatay Mustafa Kemal Üniversitesi Örneği. Selçuk İletissim, 12 (2), 708735. 
Balcı, Ş., \& Demir, Y. (2018). Televizyon İzleme Alışkanlıklarında Parasosyal Etkileşim Etkisi İle Yalnızlık Arasındaki İlişki . Iletişsim Kuram ve Araştırma Dergisi , 47, 386-408.

Balcı, Ş., \& Öğüt, N. (2018). Kültürlerarası Etkililik Düzeyinin Bazı Belirleyicileri: "Konya Örneğinde Saha Araştırması". Uluslararası Sosyal Araştırmalar Dergisi, 11 (57), 498-509.

Baş, G. ( 2010 ). An Investigation of the Relationship between Shyness and Loneliness Levels of Elementary Students in a Turkish Sample. International Online Journal of Educational Sciences, 2 (2), 419-440.

Bekiroğlu, O., \& Balcı, Ş. (2014). Kültürlerarası İletişim Duyarlılığının İzlerini Aramak: "İletişim Fakültesi Öğrencileri Örneğinde Bir Araştırma". Türkiyat Araştırmalar Dergisi, 35, 429459.

Bozkaya, M., \& Erdem Aydın, İ. (2010). Kültürlerarası İletişim Kaygısı:Anadolu Üniversitesi Erasmus öğrencileri Değişim Programı örneği. İstanbul Üniversitesi Illetişsim Fakültesi Dergisi, 39, 29-42.

Chen, G.-M. (1997). A Review of the Concept of Intercultural Sensitivity. Paper presented at the biennial convention of Pacific and Asian Communication Association, January, Honolulu, Hawaii., 1-16.

Çakıcı, C., Kızılırmak, İ., Samatova, G., \& Kızılay, K. S. (2017). Bişkek'teki Otel Çalışanlarının Kültürlerarası İletişim Kaygıları. MANAS Sosyal Araştırmalar Dergisi, 6 (5), 68-77.

Çakır, V., \& Çakır, V. (2011). Yalnızlık ve Televizyon Kullanımı. Selçuk Illetişim, 7 (1), 131-147.

Demir, A. (1989). UCLA yalnızlık ölçeğinin geçerlik ve güvenirliği. Psikoloji Dergisi, 7 (23), 1418.

Demir, Y., \& Kutlu M. (2016). Üniversite Öğrencilerinde Sosyal Etkileşim Kaygısı İle Mutluluk Arasındaki İlişki: Yalnızlığın Aracı Rolü. Gazi Üniversitesi Gazi Eğitim Fakültesi DergisiGEFAD, 36 (1), 195-210.

Downs, V., Javidi, M., \& Nussbaum, J. (1987). Communication Apprehension and Loneliness in Older Adults: An Empirical Test of Socio-Environmental Theory. Communication Research Reports, 4 (2), 38-42.

Duy, B. (2003). Bilişsel-Davranışçı Yaklaşıma Dayalı Grupla Psikolojik Danışmanın Yalnızlık ve Fonksiyonel Olmayan Tutumlar Üzerine Etkisi. Yayımlanmamış Doktora Tezi, Ankara Üniversitesi Eğitim Bilimleri Enstitüsü, Ankara.

Fall, L., Kelly, S., MacDonald, P., Primm, C., \& Holmes, W. (2013). Intercultural Communication Apprehension and Emotional Intelligence in Higher Education: Preparing Business Students for Career Success. Business Communication Quarterly, 76 (4), 412-426.

George, D., \& Mallery, P. (2010). SPSS for Windows Step by Step: A Simple Guide and Reference 17.0 Update (10th Edition b.), Boston: Pearson.

Gerson, A. C., \& Perlman, D. (1979). Loneliness and expressive communication. Journal of Abnormal Psychology, 88, 258-261.

Gudykunst, W. B. (1995). I Anxiety/ Uncertainty Management (AUM) theory: Current status. In R. L. Wiseman (Ed.), Intercultural Communication Theory (pp. 8-58), Thousand Oaks, CA: Sage Publications.

Gudykunst, W. B. (2005). Theories of intercultural communication. China Media Research, 1, 6175 . 
Heinz, M. (2018). Communicating While Transgender:Apprehension, Loneliness, and Willingness to Communicate in a Canadian Sample. SAGE Open - Original Manuscript, 1-17.

Karadağ, E., \& Sölpük, N. (2018). Türkiye'de Yapılan Çalışmalarda Depresyon ve Kaygı İlişkisi: Bir Metaanaliz Çalışması. Dusunen Adam The Journal of Psychiatry and Neurological Sciences, 31, 163-176.

Karakoç, E., \& Taydaş, O. (2013). Bir Serbest Zaman Etkinliği Olarak Üniversite Öğrencilerinin İnternet Kullanımı İle Yalnızlık Arasındaki İlişki “Cumhuriyet Üniversitesi Örneğì”. Selçuk İletişim, 7 (4), 33-45.

Kartarı, A. (2014). Kültür, Farklllık ve İletişim, Kültürlerarsı İletişimin Kavramsal Dayanakları. İstanbul: İletişism Yayınları.

Kassing, J. -W. (1997). Development of the intercultural willingness to communicate scale. Communication Research Reports, 14 (4), 399-407.

Kılıç, Ş. D., \& Alver, B. (2017). Üniversite Öğrencilerinin Yalnızlık Düzeyleri Ve Psikolojik Dayanıklılıkları Arasındaki İlişkilerin Bazı Değişkenlere Göre İncelenmesi. IJETSAR (International Journal Of Education Technology and Scientific Researches), 3, 116-147.

Kim, Y.-Y. (1988). Communciation and cross-cultural adaptation. Clevedon, England: Multilingual Matters.

Lin, Y., \& Rancer, A.-S. (2003). Ethnocentrism, Intercultural Communication Apprehension, Intercultural Willingness-to-Communicate, and Intentions to Participate in an Intercultural Dialogue Program: Testing a Proposed Model. Communication Research Reports, 20 (1), 62-72.

Mercan, N., Oyur, E., Alamur, B., Gül, S., \& Bengül, S. (2012). İşyeri Yalnızlığı ve Sosyal Fobi Arasındaki İlişkiye Yönelik Bir Araştırma. Organizasyon ve Yönetim Bilimleri Dergisi, 4,1,213-226.

Neuliep, J., \& Ryan, D. (1998). The influence of intercultural communication apprehension and socio-communicative orientation on uncertainty reduction communication apprehension and socio-communicative orientation on uncertainty reduction. Communication Quarterly, 46 (1), 88-99.

Neuliep, J., \& McCroskey, J. (1997). The Development of Intercultural and Interethnic Communication Apprehension Scales. Communication Research Reports, 14 (2), 145-156.

Olkun, E., \& Öğüt, N. (2018). Üniversite Öğrencilerinin Kültürlerarası İletişim Kayg1 Düzeyi: Selçuk Üniversitesi Örneği. The Journal of Academic Social Science Studies, 69, 513-525.

Öğüt, N. (2018). Kültürlerarası İletişim ve Duyarlılık. Konya: Literatürk Yayınları.

Peplau, L. A., \& Perlman, D. (1979). Blueprint for a Social Psychological Theory of Loneliness. In M. Cook and G. Wilson (Eds.). Love and Attraction, Oxford, England: Pergamon, 99-108.

Perlman, D., \& Peplau, L. A. (1981). Toward a Social Psychology of Loneliness. In R. Gilmour, \& S. Duck (Eds.), Personal Relationships: 3. Relationships in Disorder (pp. 31-56). London: Academic Press.

Perlman, D., \& Peplau, L. A. (1984). Loneliness Research: A Survey of Empirical Findings. In L. A. Peplau and S. Goldston (Eds.), Preventing the Harmful Consequences of Severe and Loneliness (pp 13-46). U.S. Government P r i n t i n g Office.

Perlman, D., \& Peplau, L. A. (1998) Loneliness. In Friedman, H.S. (Ed.), Encyclopedia of Mental Health, Vol. 2 (pp. 571-581), San Diego: Academic Press. 
Portalla, T., \& Chen, G.-M. (2010). The Development and Validation of the Intercultural Effectiveness Scale. Intercultural Communication Studies, 19 (3), 21-37.

Quero, L. N. (2014). Comparative Analysis of Intercultural Communication Apprehension Displayed by International Students in the US Interacting with American Students and Other Internationals. Unpublished Master Dissertation. The Rochester Institute of Technology School of Communication.

Russell, D., Letitia, A.-C., \& Carolyn, E. (1980). The revised UCLA Loneliness Scale: Concurrent and discriminant validity evidence. Journal of Personality and Social Psychology, 39 (3), 472-480.

Russell, D., Peplau, L.-A., \& Ferguson, M. (1978). Developing a Measure of Loneliness. Journal of Personality Assessment, 42 (3), 290-294.

Sathiensathidkun, A. (2015). Intercultural Communication Apprehension and Communication Apprehension among Thai Physicians at Hospitals in Bangkok. Unpublished Master Dissertation, Thammasat University.

Softa, H.-K., Öztürk, A., Dindaş, İ., \& Göçmen, M. (2015). "Kastamonu 1 No'lu Aile Sağlığ1 Merkezine Başvuran Yaşlıların Yalnızlık Düzeyini Etkileyen Bazı Faktörlerin İncelenmesi”. Yaşlı Sorunları Araştırma Dergisi, 2, 88-97.

Yağbasan, M. (2016). Almanya ve Türkiye Özelinde Kültürlerarası iletişim. Konya: LiteraTürk Yayınları.

Yaşar, M. (2007). Yalnızlık. Fırat Üniversitesi Sosyal Bilimler Dergisi, 17 (1), 237-260.

Yıldız, D., \& Uzunsakal, E. (2018). Alan Araştırmalarında Güvenilirlik Testlerinin Karşılaştırılması ve Tarımsal Veriler Üzerine Bir Uygulama. Uygulamalı Sosyal Bilimler Dergisi, 1, 14-27.

Zakahi, W., \& Duran, R. (1982). All the lonely people: The relationship among loneliness, communicative competence, and communication anxiety. Communication Quarterly, 30 (3), 203-209.

Zakahi, W., \& Duran, R. (1985). Loneliness, Communicative Competence, and Communication Apprehension: Extension and Replication. Communication Quarterly, 33 (1), 50-60. 